\section{Congress awards few stars}

\section{Washington}

THE annual political showdown between the US Congress and the administration over funds for the Strategic Defense Initiative (SDI) is likely to leave the Department of Defense (DoD) with a little less to spend on the programme next year than the $\$ 4,000$ million it spent this year. President George Bush inflicted the first wound to SDI when he "reluctantly" sliced $\$ 1,000$ million from the the DoD's request of $\$ 5.6$ million next year, in a round of across-the-board spending cuts. Not unpredictably, when it was the turn of the House of Representatives last week, the SDI programme emerged decidedly leaner at $\$ 3,100$ million. This week it is in the hands of the Senate where SDI has more friends than in the House; the Senate Armed Services Committee has recommended that a budget of $\$ 4,600$ million be approved. After that, if the

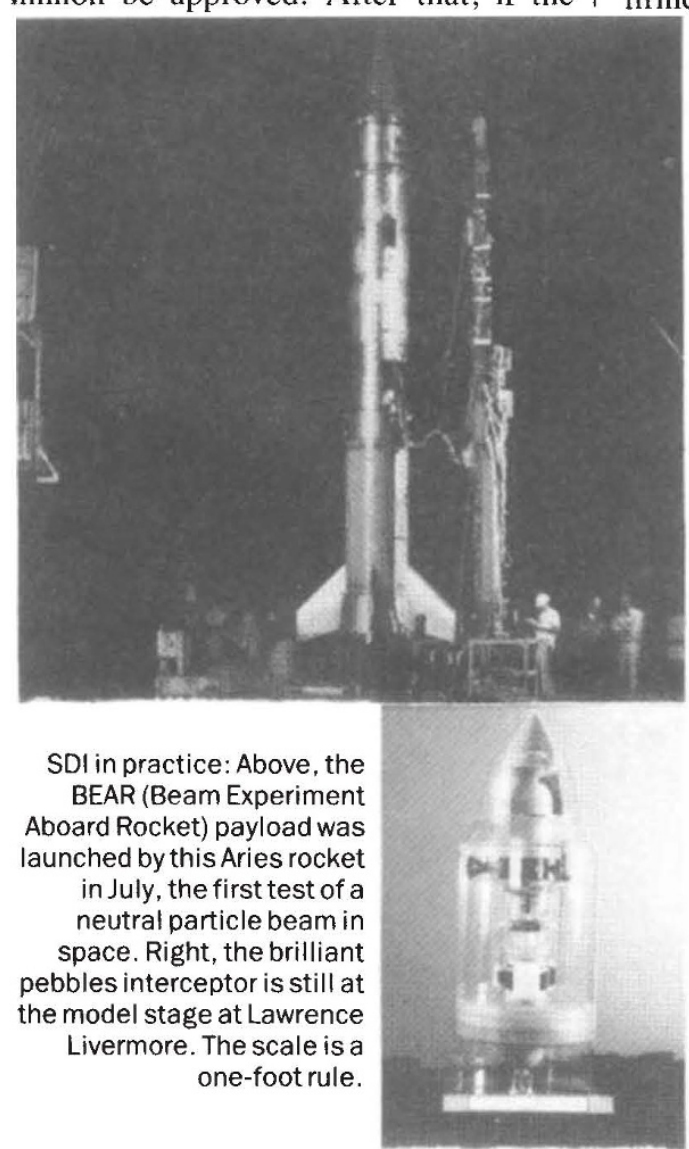

research on newer concepts, especially the 'brilliant pebble' interceptor rockets, would be cut. These may be exactly the effects that Congress hopes for in its wish to maintain a research programme but postpone deployment. Bush, who is "personally and deeply committed" to SDI, said he was disappointed at last week's cuts and emphasized the importance of SDI as a bargaining chip in arms negotiations. Few now consider former President Reagan's vision of a comprehensive defence shield to be realistic.

Congress has cut the SDI budget request every year but one since the programme began in 1984. But opposition is stiffening as deployment approaches. The cuts were approved this year by a higher majority than in previous years, although no restrictions were placed on specific programmes. And the House of Representatives reaffirmed its opposition deployment last week by passing unanimously an amendment urging Bush to seek the dismantling of an existing Soviet antisatellite weapon (ASAT), to negotiate for the "strictest possible limitations" on ASATs. It also called for a comprehensive report on US antisatellite weapon programmes including an assessment of the antisatellite potential of SDI technology. A strict ASAT limitation treaty would restrict deployment of SDI systems as well as blocking several ASAT programmes.

The amendment also called for a report on the interference of orbiting nuclear reactors on scientific satellites. This is seen as another backdoor route to blocking SDI deployment as nuclear reactors in space will be essential to provide power for space-based weapons such as charged particle beams and free electron lasers. In the House of Representatives, legislation is pending that would call for an international treaty to prohibit the use of nuclear power in orbit, except in deep space missions.

Since 1984, \$17,000 million has been spent on SDI research and the Pentagon wants to double that over the next five years. An estimated ritual of previous years is repeated, the House and Senate will compromise by splitting the difference.

The Strategic Defense Initiative Organisation (SDIO) says that with less than $\$ 4,000$ million the longer-term technologies will not be available in time to offset Soviet countermeasures to the first phase of the strategic defence system. It also says that a decision on deployment would be delayed by two years, the workforce would be cut by more than 6,000 , and
$\$ 80,000$ million will then be needed for deployment. These requests are unrealistically high, and future tight budgets are likely to restrict the research and testing on which to base decision-making, pushing back the deadline for a decision on deployment.

Critics of SDI are likely to focus opposition on a series of major field tests planned to take place over the next two years.

Some of the trials may be argued to violate the Anti-Ballistic Missile Treaty.

\section{Star wars in 1989}

\section{Boost phase defence}

Surveillance and Tracking System: Satellites equipped with a telescope and sensor that detect and track ballistic missiles will be the first SDI systems deployed.

Space-based interceptors: Testing has begun of guided interceptor rockets that will destroy missiles as they rise through the atmosphere by colliding with them at high velocity. The final plan calls for 300 orbiting 'garages' each containing multiple rockets.

Brilliant pebbles: Thousands of threefoot long interceptor rockets each with a sensor and computer are planned to orbit the Earth in swarms. In the event of an attack, each would independently seek out incoming missiles and destroy them by impact.

Chemical space-based laser: Orbiting platforms could direct extremely powerful infrared laser beams onto missiles. The 'Zenith Star' space experiment with the Alpha chemical laser is scheduled for the mid-1990s.

\section{Boost - Midcourse defence}

neutral particle beams: Warheads are destroyed with beams of high-energy atomic particles. The first test in space was carried out this year but a practical weapon could not be ready before the end of the century.

Space-based electromagnetic rail gun: rail guns could destroy weapons with 2 kilogram projectiles fired at 2-3 kilometres per second. To destroy missiles in boost phase would requires speeds of 12 kilometres per second. Ground tests have reached projectile velocities of 2 kilometres per second with 150-gram projectiles. making full-scale development unlikely before the late 1990s.

- Free electron laser: The free-electron laser, which would destroy warheads with a beam of high-energy electrons, is the most promising of the ground-based beam weapons. There are two competing types; this year SDIO will choose between them and award a contract for construction.

\section{Midcourse - Terminal defence}

The Airborne Optical Adjunct: Modified Boeing 767 aircraft will be equipped with long-wave infrared and optical sensors. About 40 would cover the United States and detect incoming warheads and separate out decoys. The first test flight is planned for 1990 .

Exo-atmospheric and endo-atmospheric reentry interceptor subsystem: Six-foot long interceptors launched from the ground would destroy weapons by impact before or after they enter the atmosphere. The first of a series of tests is due this year.

They include further tests in space of neutral particle beam lasers, the first flight test of an endo-atmospheric interceptor, the first flight of the airborne optical adjunct and the first major tests of the effects of the atmosphere on the freeelectron laser.

Christine McGourty 